\title{
Studies of Acetate Interaction Reactions Manganese and copper with $\mathrm{N}$-methylurea
}

\author{
ML Yeritsyan*, RA Karamyan, VM Mavisakalyan and AM Arustamyan \\ Armenian State Pedagogical University, Russia \\ *Corresponding author: ML Yeritsyan, Armenian State Pedagogical University after Kh. Abovyan, Yerevan0010 Yerevan, \\ Tigran Mets 17, Russia
}

\begin{tabular}{|c|}
\hline ARTICLE INFO \\
\hline Received: 慧 September 13, 2019 \\
\hline Published: 慧September 26, 2019 \\
\hline
\end{tabular}

Citation: ML Yeritsyan, RA Karamyan, VM Mavisakalyan, AM Arustamyan. Studies of Acetate Interaction Reactions Manganese and copper with N-methylurea. Biomed J Sci \& Tech Res 21(4)-2019. BJSTR. MS.ID.003627.

\begin{abstract}
The kinetic laws of the condensation reaction between metal acetates are investigated: - manganese and copper $\mathrm{Me}\left[\mathrm{OC}(\mathrm{O}) \mathrm{CH}_{3}\right]_{2}\left(\mathrm{Me}(\mathrm{Ac})_{2}\right)$ with $\mathrm{N}$-methylolurea. The numerical values of the rate constant at various temperatures and the activation energy of the condensation process between these compounds are estimated. A conclusion is drawn regarding the activity of the acetates of the studied metals in the reactions of their interaction with $\mathrm{N}$-methylolurea.
\end{abstract}

Keywords: N-Methylolurea; Manganese and Copper Acetates; Rate Constant; Activation Energy

\section{Introduction}

The synthesis and study of the properties of alcoholates of metals of variable valence has been the subject of many works, of which the authors' work deserves special attention [1-3]. Alcoholates of metals of variable valency are interesting in that they exhibit catalytic activity both in the synthesis of individual organic compounds and in the complex radical polymerisation of vinyl monomers [4,5]. So, in the aforementioned work [4], in particular, a high catalytic activity of metal alcoholates-manganese and copperwas noted. Meanwhile, in the scientific literature there is practically no data on a quantitative assessment of the formation of alcoholates from acetates of the above metals. This report is devoted to a detailed study of the reaction between metal acetates: -manganese and copper with $\mathrm{N}$-methylurea at various temperatures, followed by determination of both the rate constant and the activation energy of their interaction.

\section{Experimental Part}

Mn $\left[\mathrm{OC}(\mathrm{O}) \mathrm{CH}_{3}\right]_{2} \cdot 4 \mathrm{H}_{2} \mathrm{O}$ and $\mathrm{Cu}\left[\mathrm{OC}(\mathrm{O}) \mathrm{CH}_{3}\right]_{2} \cdot \mathrm{H}_{2} \mathrm{O}$ were used in the studies "chda" brand, $\mathrm{N}$ - methylolurea was synthesized according to the method described in detail in [6] and identified by IR spectroscopy on a NIKOLET / FT-IRNEXUS spectrophotometer. Getting MMch. $15 \mathrm{~g}$ ( $0.25 \mathrm{~mol})$ of urea and $20 \mathrm{~g}$ of a $38 \%$ aqueous formaldehyde solution $(0.25 \mathrm{~mol})$ are loaded into the reactor and stirred at a temperature of $(35 \pm 0.5)$ 0C for 30 minutes.
Then under low pressure (15-20) mm. Hg. Art. at a temperature of $(45-50)^{\circ} \mathrm{C}$ water is distilled off. The white precipitate (MMh) is repeatedly washed and recrystallized with ethanol and dried under pressure $(15-20) \mathrm{mm} \mathrm{Hg}$. at $50-60^{\circ} \mathrm{C}$ until a constant mass is achieved. The yield of MMh is $93 \%$, the melting point (Tm) is (111 $\pm 0.5)^{\circ} \mathrm{C}$. The elemental composition in (\%) was established: C26.6(26.67); H6.8(6.66); N-31.2(31.11). In our studies, a mixture of dimethylformamide (DMF) with water in a volume ratio (1:1) was used as an MMh solvent. Acetic acid obtained during the reaction was determined by volumetric analysis i.e. titration of $4 \mathrm{ml}$ of the sample with $0.1 \mathrm{~N}$ aqueous alkali solution $(\mathrm{NaOH})$ prepared from fixanal. The indicator was phenophthalein. The total volume of the reaction mixture was $50 \mathrm{ml}$.

\section{The Discussion of The Results}

The kinetic regularities of the accumulation of acetic acid formed in the reaction between $\mathrm{Mn}\left[\mathrm{OC}(\mathrm{O}) \mathrm{CH}_{3}\right]_{2}\left(\mathrm{Mn}(\mathrm{Ac})_{2}\right)$ and $\mathrm{N}$-methylolurea (MMh) at various temperatures studied, depending on the reaction time, are given in Table 1. From the data in Table 1 it follows that the reaction between $\mathrm{Mn}(\mathrm{Ac})_{2}$ and $\mathrm{MMh}$ is a second-order reaction, and the rate constant is described [7] by the equation below

$$
k=\frac{1}{t} \cdot \frac{1}{A_{o}-B_{o}} \ln \frac{B_{o}\left(A_{o}-x\right)}{A_{o}\left(B_{o}-x\right)}
$$


Using the data in Table 1 and plotting the dependencies $\frac{1}{A_{o}-B_{o}} \ln \frac{B_{o}\left(A_{o}-x\right)}{A_{o}\left(B_{o}-x\right)}$ from $t$ (reaction time) are estimated and presented in Table 2 values of the reaction rate constant between $\mathrm{Mn}(\mathrm{Ac})_{2}$ and MMh at different temperatures. Induction periods shown in Figure 1 regularities can be attributed to the lifetime of the intermediate compound formed upon the interaction of MMh with $\mathrm{Mn}(\mathrm{Ac})_{2}$. The probable structure of the intermediate compound and its further decay can be represented as:

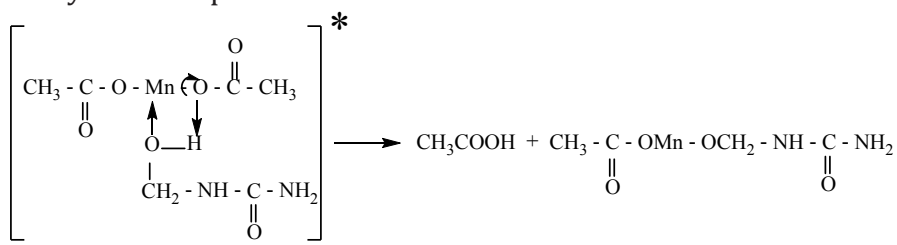

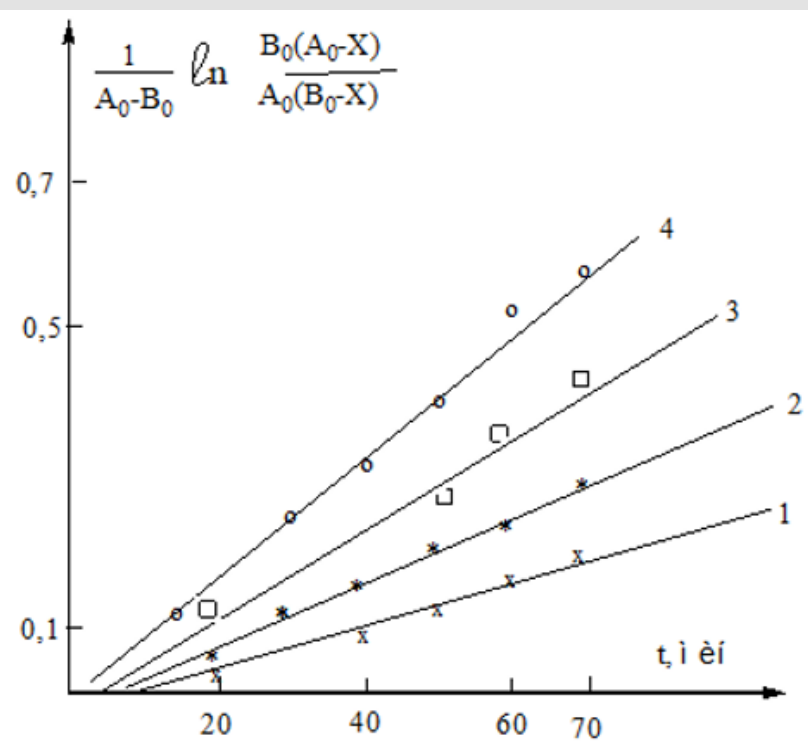

Figure 1: Dependence $\frac{1}{A_{o}-B_{o}} \ln \frac{B_{o}\left(A_{o}-x\right)}{A_{o}\left(B_{o}-x\right)}$ from $\mathrm{t}(\mathrm{min})$ at various temperatures: $1-\left(60^{\circ} \mathrm{C}\right) ; 2-\left(65^{\circ} \mathrm{C}\right) ; 3^{-}\left(70^{\circ} \mathrm{C}\right) ; 4-\left(75^{\circ} \mathrm{C}\right)$.

Table 1: Kinetics of the reaction between $\mathrm{Mn}(\mathrm{Ac})_{2}$ and $\mathrm{MMh}$ at different temperatures $[\mathrm{MMh}] 0=(\mathrm{A}) 0=0.6 \mathrm{~mol} / \mathrm{l} ;\left[\mathrm{Mn}(\mathrm{Ac})_{2}\right] 0=$ (V) 0-0.3 $\mathrm{mol} / \mathrm{L}$.

\begin{tabular}{|c|c|c|c|c|c|c|c|c|}
\hline \multirow{3}{*}{$\begin{array}{l}\frac{N_{o}}{N_{o}} \\
\frac{n}{n}\end{array}$} & \multicolumn{8}{|c|}{ The concentration of acetic acid $(x)$ during the reaction time Mn (AC) 2 with MMh at temperatures: } \\
\hline & \multicolumn{2}{|c|}{$600 \mathrm{C}$} & \multicolumn{2}{|c|}{$650 \mathrm{C}$} & \multicolumn{2}{|c|}{$700 \mathrm{C}$} & \multicolumn{2}{|c|}{$750 \mathrm{C}$} \\
\hline & t.min & $X \cdot \frac{M}{\pi}$ & t.min & $X \cdot \frac{M}{\pi}$ & t.min & $X \cdot \frac{M}{\pi}$ & t.min & $X \cdot \frac{M}{\pi}$ \\
\hline 1 & 8,0 & 0,004 & 15 & 0,001 & 20 & 0,014 & 15 & 0,018 \\
\hline 2 & 30,0 & 0,008 & 20 & 0,008 & 30 & 0,018 & 20 & 0,02 \\
\hline 3 & 40,0 & 0,014 & 25 & 0,012 & 40 & 0,024 & 30 & 0,032 \\
\hline 4 & 50,0 & 0,022 & 30 & 0,014 & 50 & 0,042 & 40 & 0,044 \\
\hline 5 & 60,0 & 0,025 & 40 & 0,022 & 60 & 0,052 & 50 & 0,062 \\
\hline 6 & 70,0 & 0,032 & 50 & 0,032 & 70 & 0,067 & 60 & 0,08 \\
\hline 7 & - & - & 60 & 0,038 & - & - & 70 & 0,088 \\
\hline 8 & - & - & 70 & 0,045 & - & - & - & - \\
\hline
\end{tabular}

Table 2: The values of the reaction rate constant between $\mathrm{MMh}$ and $\mathrm{Mn}(\mathrm{Ac})_{2}$ at various temperatures.

\begin{tabular}{|c|c|c|c|c|c|}
\hline $\mathrm{T}\left({ }^{0} \mathrm{~K}\right)$ & 333 & 338 & 343 & 348 \\
\hline $\mathrm{k} \times 10^{5}(1 / \mathrm{mol} \mathrm{sec})$ & & 5,3 & 6,0 & 10,02 & 14,6 \\
\hline
\end{tabular}

Using the Arrhenius equation $k=A e^{-E a / R T}$ (2) [7] and constructing the dependence of $\ln k$ OT $\left(\frac{1}{T}\right)$ (Figure 2) based on the numerical values of $\mathrm{k}$ of (Table 2), the activation energy (Ea) the reaction of the interaction of MMC with $\mathrm{Mn}(\mathrm{Ac})_{2}$, which turned out to be equal to $(23 \pm 2) \mathrm{kcal} / \mathrm{mol}$. The data in Table 3 indicate that the reaction between $\mathrm{Cu}(\mathrm{Ac})_{2}$ and $\mathrm{MMh}$, like the reaction of manganese acetate $\mathrm{Mn}(\mathrm{Ac})_{2}$ with $\mathrm{MMh}$, is a second-order reaction, and the rate constant is described by equation (1). Using the data in (Table 3) and plotting the dependencies $\frac{1}{A_{o}-B_{o}} \ln \frac{B_{o}\left(A_{o}-x\right)}{A_{o}\left(B_{o}-x\right)}$ from $\mathrm{t}$ (reaction time) are estimated and presented in (Table 4) values of the reaction rate constant between $\mathrm{Cu}(\mathrm{Ac})_{2}$ and $\mathrm{MMh}$ at different temperatures (Figure 3). Yeritsyan M.L. Using the data of Table 4 
and plotting the dependence of $\ln k O T\left(\frac{1}{T}\right)$ (Figure 4), the value of the activation energy of the reaction between $\mathrm{Cu}(\mathrm{Ac})_{2}$ and $\mathrm{MMh}$ was estimated, which turned out to be $10 \pm 1.5 \mathrm{kcal} / \mathrm{mol}$. Thus, from a comparison of the numerical values of the interaction activation energy, we can conclude that copper acetate $\left(\mathrm{Cu}(\mathrm{Ac})_{2}\right)$ in the reaction with $\mathrm{MMh}$ is more active than manganese acetate $\left(\mathrm{Mn}(\mathrm{Ac})_{2}\right)$.

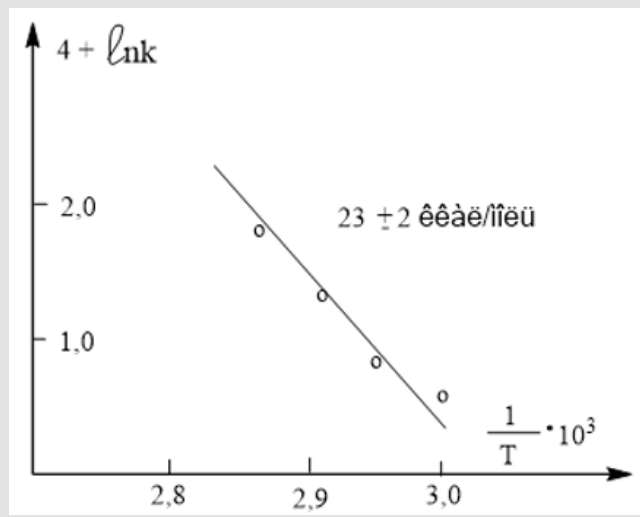

Figure 2: Dependence $k$ OT $\left(\frac{1}{T}\right)$.

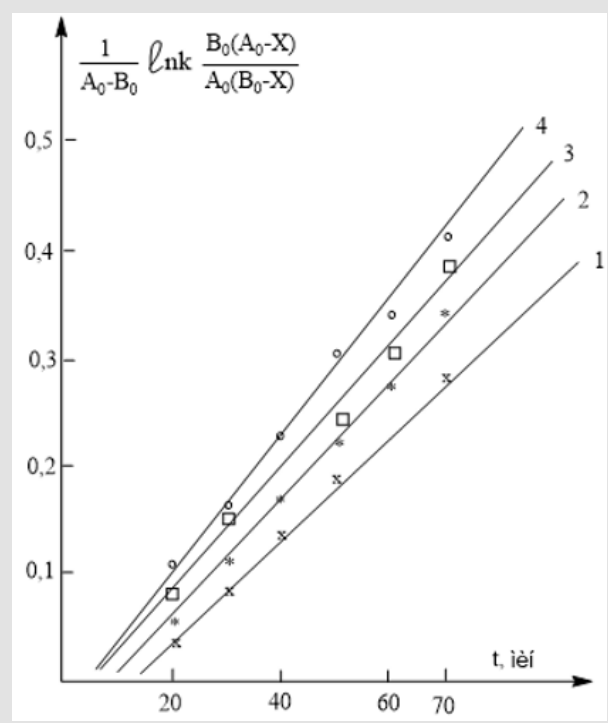

Figure 3: Dependence $\frac{1}{A_{o}-B_{o}} \ln \frac{B_{o}\left(A_{o}-x\right)}{A_{o}\left(B_{o}-x\right)}$ from OT t (min) at various temperatures: 1- (600C); 2-(650C); 3- (700C); 4- (750C)..

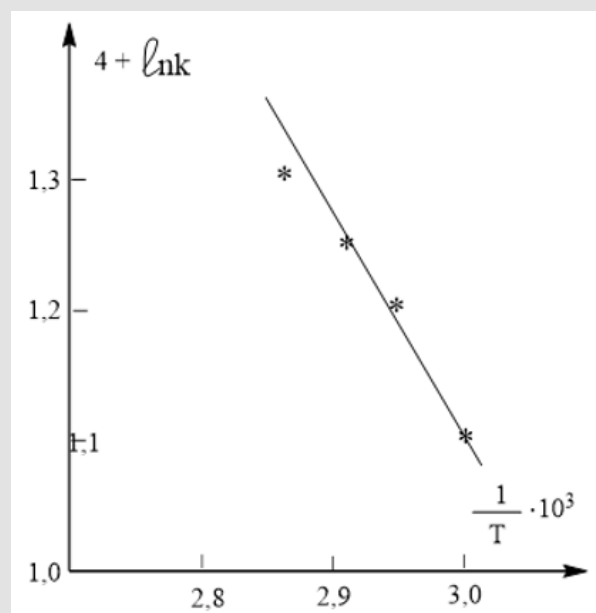

Figure 4: Dependence ln $k$ OT $\left(\frac{1}{T}\right)$. 
Table 3: The change in the concentration of acetic acid over the course of the reaction between $\left[\mathrm{Cu}(\mathrm{Ac})_{2}\right]$ and $(\mathrm{MMh})$ at various temperatures studied: $[\mathrm{MMh}] 0=(\mathrm{A}) 0=0.6 \mathrm{~mol} / \mathrm{l}$; $\left[\mathrm{Cu}(\mathrm{Ac})_{2}\right] 0=(\mathrm{V}) 0=0.3 \mathrm{~mol} / \mathrm{L}$.

\begin{tabular}{|c|c|c|c|c|c|c|c|}
\hline \multicolumn{8}{|c|}{ The concentration of acetic acid $(\mathrm{x})$ in time the reaction of $\mathrm{Cu}(\mathrm{AC})_{2}$ with $\mathrm{MMh}$ at temperatures: } \\
\hline \multicolumn{2}{|c|}{$60^{\circ} \mathrm{C}$} & \multicolumn{2}{|c|}{$65^{\circ} \mathrm{C}$} & \multicolumn{2}{|c|}{$70^{\circ} \mathrm{C}$} & \multicolumn{2}{|c|}{$75^{\circ} \mathrm{C}$} \\
\hline t.min & $X \cdot \frac{M}{\pi}$ & t.min & $X \cdot \frac{M}{\pi}$ & t.min & $X \cdot \frac{M}{\pi}$ & t.min & $X \cdot \frac{M}{\pi}$ \\
\hline 20 & 0,006 & 9 & 0,04 & 10 & 0,007 & 10 & 0,009 \\
\hline 30 & 0,015 & 20 & 0,01 & 20 & 0,015 & 20 & 0,015 \\
\hline 40 & 0,025 & 30 & 0,019 & 30 & 0,025 & 30 & 0,034 \\
\hline 50 & 0,032 & 40 & 0,027 & 40 & 0,037 & 40 & 0,041 \\
\hline 60 & 0,043 & 50 & 0,036 & 50 & 0,044 & 50 & 0,047 \\
\hline \multirow[t]{2}{*}{70} & 0,045 & 60 & 0,044 & 60 & 0,048 & 60 & 0,052 \\
\hline & & 70 & 0,054 & 70 & 0,051 & 70 & 0,069 \\
\hline
\end{tabular}

Table 4: The values of the reaction rate constant between $\mathrm{Cu}(\mathrm{Ac})_{2}$ and $\mathrm{MMh}$. at various temperatures.

\begin{tabular}{|c|c|c|c|c|}
\hline $\mathrm{T}(0 \mathrm{~K})$ & 333 & 338 & 343 & 348 \\
\hline $\mathrm{k} \times 10^{5}(\mathrm{l} / \mathrm{mol} \mathrm{sec})$ & 8,2 & 9,1 & 9,5 & 10,02 \\
\hline
\end{tabular}

\section{References}

1. ML Yeritsyan, RR Karapetyan, KA Martirosyan, RA Karamyan, AG Khachatryan, et al. (2011) Scientific notes of YSU, chemistry and biology 3: 16

2. ML Yeritsyan, SM Petrosyan, RA Karamyan, LM Yeritsyan (2014) Physicochemistry of polymers, synthesis, properties and applications. Tver Bulletin of TSU 20: 284.

3. RA Qaramyan, IN Sirekanyan, ML Yeritsyan (2018) Amino alcohols and chelates on their basic.- Proceedings of the Yerevan State Universiti. chemical and biological Sciences 52(8): 96.

\section{ISSN: 2574-1241}

DOI: 10.26717/BJSTR.2019.21.003627

ML Yeritsyan. Biomed J Sci \& Tech Res

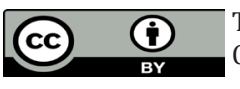

This work is licensed under Creative Commons Attribution 4.0 License

Submission Link: https://biomedres.us/submit-manuscript.php
4. NV Smirnov, GA Gabrielyan L, S Holbraich (1990) High molecular weight compound 32(11): 2314.

5. VA Kabanov, VP Teeth, Yu D Semchikov (1987) Complex radical polymerization pp. 256.

6. AF Nikolaev (1964) Synthetic polymers and plastics based on them. Publishing house "Chemistry". 378.

7. NM Emanuel, DG Knorre (1962) The course of chemical kinetics. Graduate School. Moscow pp. 168.

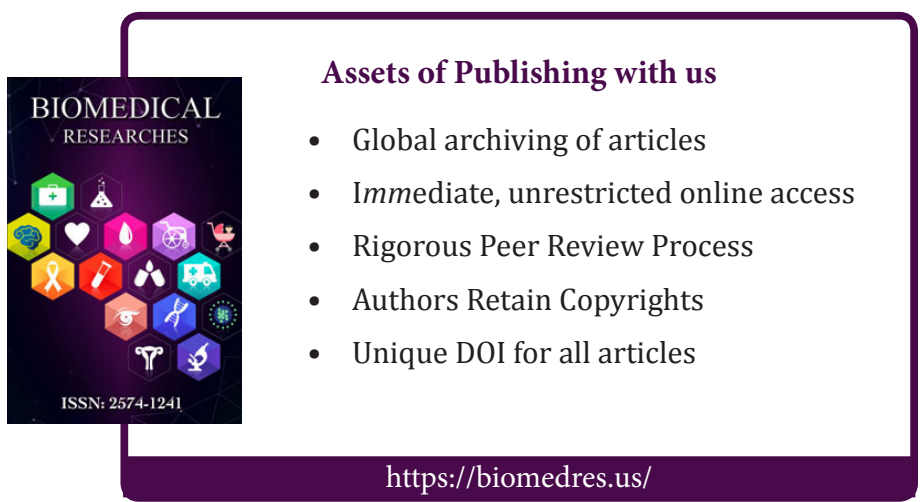

